Summary: Implant failure is one of the major concerns in the biomaterials field. Several factors have been related to the fail but in general these biomaterials do not exhibit comparable physical, chemical or biological properties to natural tissues and ultimately, these devices can lead to chronic inflammation and foreign-body reactions. Starch-based biodegradable materials and composites have shown promising properties for a wide range of biomedical applications as well as a reduced capacity to elicit a strong reaction from immune system cells in vitro. In this work, blends of corn starch with ethylene vinyl alcohol (SEVA-C), cellulose acetate (SCA) and polycaprolactone (SPCL), as well as hydroxyapatite (HA) reinforced starch-based composites, were investigated in vivo. The aim of the work was to assess the host response evoked for starch-based biomaterials, identifying the presence of key cell types. The tissues surrounding the implant were harvested together with the material and processed histologically for evaluation using immunohistochemistry. At implant retrieval there was no cellular exudate around the implants and no macroscopic signs of an inflammatory reaction in any of the animals. The histological analysis of the sectioned interface tissue after immunohistochemical stain- ing using ED1, ED2, CD54, MHC class II and $\alpha / \beta$ antibodies showed positively stained cells for all antibodies, except for $\alpha / \beta$ for all the implantation periods, where it was different for the various polymers and for the period of implantation. SPCL and SCA composites were the materials that stimulated the greatest cellular tissue responses, but generally biodegradable starch-based materials did not induce a severe reaction for the studied implantation times, which contrasts with other types of degradable polymeric biomaterials.

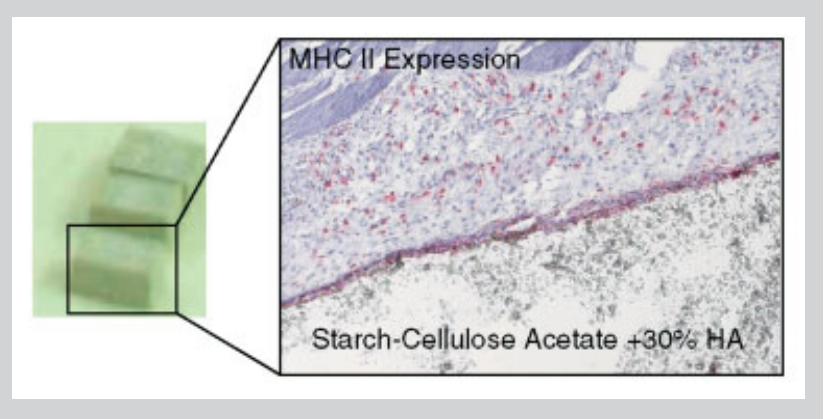

\title{
An In Vivo Study of the Host Response to Starch-Based Polymers and Composites Subcutaneously Implanted in Rats
}

\author{
Alexandra P. Marques, ${ }^{* 1,2}$ Rui L. Reis, ${ }^{1,2}$ John A. Hunt ${ }^{3}$ \\ ${ }^{1}$ Department of Polymer Engineering, University of Minho, Campus de Azurém, 4810-058 Guimarães, Portugal \\ E-mail: apmarques@dep.uminho.pt \\ 23B's Research Group-Biomaterials, Biodegradables, Biomimetics, University of Minho, Campus de Gualtar, \\ 4710-057 Braga, Portugal \\ ${ }^{3}$ Clinical Engineering, UKCTE, University of Liverpool, Liverpool L69 3GA, UK
}

Received: January 19, 2005; Revised: May 23, 2005; Accepted: May 24, 2005; DOI: 10.1002/mabi.200500010

Keywords: biodegradable; biomaterials; in vivo; inflammation; starch

\section{Introduction}

The challenge in the development of new devices for orthopaedics is to ensure long-term stability, anchorage and function. The loosening of joint prosthesis, resulting in device failure, is a major concern in the field of biomaterials for orthopaedic applications, ${ }^{[1,2]}$ with revision surgery occurring at both early and late implantation periods, depending on the cause of failure. Unpredictable adverse reactions to some commonly used traditional implants have been reported by a number of research groups. ${ }^{[3-7]}$ Key factors in device failure are believed to be the generation of wear particles and the biological response to them in periprosthetic tissues ${ }^{[2,4]}$ as well as the degradation products of biodegradable materials, both resulting in osteolytic reactions. ${ }^{[5,6,8]}$

The presence of activated macrophages ${ }^{[9-13]}$ or foreignbody giant cells, ${ }^{[9,11,13]}$ and the formation of a fibrous capsule $^{[14,15]}$ are tissue-specific responses that have been the focus of investigation in the evaluation of biomedical implants. Additionally, the evaluation of angiogene$\operatorname{sis}^{[12,13,16,17]}$ at the implant area has been realised as an important factor with significant influence in the tissue 
reaction at the polymer-tissue interface. The presence of giant cells is frequently observed ${ }^{[9,11,13]}$ and the duration and severity of the reaction may or may not compromise the role of the device. Phagocytic cells normally involved in inflammation are thought to be responsible for removing the final products of degradation. In fact, both clinical applications ${ }^{[4-6]}$ and animal studies ${ }^{[18-21]}$ have suggested that degradation products directly and indirectly affect tissue remodelling by interaction with the cells responsible for the formation of de novo tissue and through the induction of inflammatory cytokines released by activated macrophages. Since macrophages tend to engulf smaller particles $^{[22]}$ and form multinuclear giant cells to surround larger objects, ${ }^{[23]}$ particle size was also suggested to be an important factor in the different tissue reactions. Nonetheless, the differences in duration of the response may also be related to the material properties ${ }^{[23]}$ or with the angiogenesis around an implant ${ }^{[12,13,16,17]}$. A co-dependence has been proposed between inflammation and angiogene$\operatorname{sis}^{[24,25]}$ due to the presence of activated macrophages, capable of releasing numerous angiogenic growth factors. ${ }^{[24,26]}$ In addition, the up-regulation of adhesion molecules is known to have a significant role in the process of transvascular migration of the inflammatory infiltrate. ${ }^{[27,28]}$

Lymphocytes have also been observed at the interface of some implants. ${ }^{[18,29-31]}$ These cells are able to secrete various mediators which, in turn, have functions in immunological and inflammatory responses. Although in the majority of the cases they are identified in low numbers, lymphocytes may secrete interleukin (IL)- $4^{[32]}$ and interferon (IFN)- $\gamma^{[30]}$ which can induce macrophage fusion and activation. Studies with T-cell-deficient rats ${ }^{[30]}$ have shown that $\mathrm{T}$ cells play a major role in the formation of giant cells and in the phagocytic activity of macrophages and giant cells during the tissue response to biomaterials. Serious complications have been demonstrated when lymphocytes were the main type of cell found in a retrieved cell suspension with a low number of mononuclear phagocytes, ${ }^{[29]}$ which suggested a lymphocyte-mediated specific immunological reaction against the implant. Presenting the possibility, the tissue reaction to biomaterials might be modulated by controlling T-cell activation in the case of unwanted or secondary reactions, or in the case of too-fast degradation of biomaterials.

Starch-based materials, proposed for several biomedical applications, ${ }^{[33-36]}$ have also been shown to be degraded by $\alpha$-amylase, ${ }^{[37-39]}$ phagocytosed by macrophages, ${ }^{[38,39]}$ and have demonstrated a low inflammatory tissue reaction when implanted in both rats and mice. ${ }^{[39,40]}$ In works by other groups ${ }^{[41,42]}$ starch-based biomaterials implanted in rabbits and goats also performed well without adverse reactions.

The host response to cross-linked high-amylose starch $\left(\right.$ Contramid ${ }^{\circledR}$ ) was found to follow the main phases of the inflammatory and foreign-body responses to injuries caused by implanted devices. ${ }^{[43-46]}$ After 4 months only a small residual scar was apparent macroscopically and was related to a less severe early reaction than a skin incision and closure with suture material sham. ${ }^{[39]}$

In this work, starch-based biomaterials were subcutaneously implanted in rats for different time periods in order to evaluate their immunogenicity and the host cellular response. The tissues surrounding the implant were harvested together with the material and were analysed using immunohistochemistry. Markers for resident and recruited macrophages as well as for $\mathrm{T}$ lymphocytes were used in order to identify the types of cells and their subpopulations present in the implant area. Furthermore, markers for activated macrophages and for antigen presenting cells (APC) expressing major histocompatibility complex (MHC) class II molecules were used in order to understand the mechanisms and intensity of the tissue reaction.

\section{Materials and Methods}

\section{Materials}

The materials studied were (i) a 50/50 (wt.-\%) blend of corn starch and ethylene vinyl alcohol (SEVA-C, Novamont, Italy), (ii) a 50/50 (wt.-\%) blend of corn starch and cellulose acetate (SCA, Novamont, Italy), (iii) SCA reinforced with 10,20 and $30 \%$ (wt.) of hydroxyapatite, (iv) a 30/70 (wt.-\%) blend of corn starch and polycaprolactone (SPCL, Novamont, Italy) and (v) SPCL reinforced with 10, 20 and 30\% (wt.) of hydroxyapatite (HA). The starch used to produce the polymer was obtained from native maize. Its typical original composition was 70\% amylopectin and 30\% amylose (wt.- $\%$ ). In the composites the average size of $90 \%$ of the HA particles was found to be below $6.5 \mu \mathrm{m}$ (laser granulometry analysis). Further details on the production and characteristics of the study materials may be found in works by Bastioli et al. ${ }^{[47-49]}$

All the materials were processed by injection moulding under optimised processing conditions. Samples were cut into rectangular-shaped blocks $13 \times 10 \times 7 \mathrm{~mm}^{3}$, and a hole with $5-\mathrm{mm}$ diameter and $10-\mathrm{mm}$ length was drilled [Figure 1(A) and (B)]. Before implantation, the edges of the samples were trimmed and samples were rolled for 1 week in glass flasks to round machined edges and reduce the magnitude of edge effects.

SEVA-C composites were not used in this study in order to keep a reasonable number of animals and consequently conditions, and due to the in vitro results, which suggested being similar to the unreinforced polymer SEVA-C.

\section{Animals and Subcutaneous Implantation}

The experiments were performed in Wistar rats, anaesthetised using Immobilon. Four different materials were implanted subcutaneously in the back, two either side of the spine, for 7, 14 and $21 \mathrm{~d}$, with three repeats for each material 
A)

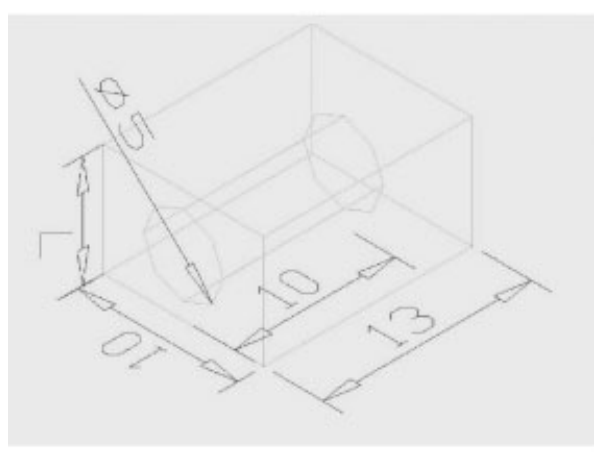

B)

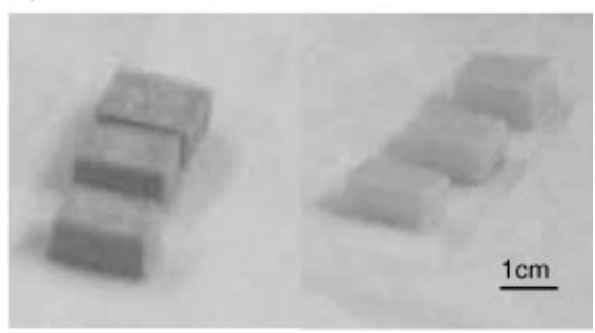

C)

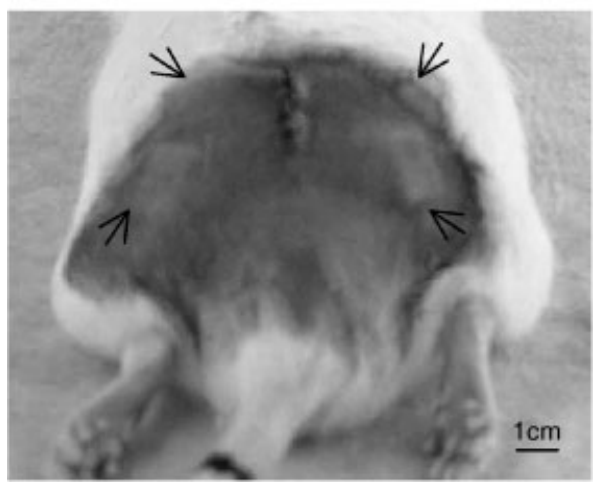

Figure 1. (A) Schematic representation of the implanted materials; (B) two of the materials implanted; (C) implant positions in the back of the rat (arrows).

per time period [Figure 1(C)]. Different positions and combinations of materials for each animal were performed to control site-specific responses and the potential effect of degradation products. At the end of the implantation period, rats were sacrificed by $\mathrm{CO}_{2}$ and the tissue surrounding the implant was carefully dissected and snap frozen using isopentane in cardice and stored at $-80^{\circ} \mathrm{C}$ until sectioned.

\section{Immunohistochemistry}

Frozen serial sections $(7 \mu \mathrm{m})$ were obtained at $-20^{\circ} \mathrm{C}$ using a 5040 Microtome (Bright, England), mounted on 3-aminopropyl-triethoxysilane (APES)-coated slides, fixed with acetone for $5 \mathrm{~min}$, air-dried and kept short term at $4{ }^{\circ} \mathrm{C}$ until staining.
Tissue sections were washed with phosphate buffer saline (PBS) solution and stained using an avidin-biotin alkaline phosphatase technique ${ }^{[50]}$ In brief: materials were exposed to rabbit serum for $30 \mathrm{~min}$, followed by primary antibodies for $45 \mathrm{~min}$ at room temperature. After that time, materials were rinsed with PBS for 5 min and incubated with biotinylated rabbit anti-mouse $\operatorname{IgG}$ antibody (Dako $\mathrm{A} / \mathrm{S}$, Denmark) for $1 \mathrm{~h}$ at room temperature. The avidin and biotinylated horseradish peroxidase complex (Vector Laboratories Ltd., UK) was added to all materials for $1 \mathrm{~h}$ and the substrate reaction was developed using the Alkaline Phosphatase Substrate Kit (Vector Laboratories Ltd., UK). Each incubation, except the rabbit serum, was followed by one wash with PBS buffer for $5 \mathrm{~min}$. Materials were washed and counterstained with haematoxylin and mounted in permanent aqueous mounting medium (Serotec Ltd, UK). Each material had one sample stained as a control replacing the primary antibody with PBS buffer.

\section{Antibodies}

Individual leukocyte cell surface molecules were identified using the following panel of mouse anti-rat monoclonal antibodies: $\alpha / \beta$ (Serotec, UK) to target the $\alpha / \beta$ T-cell antigen receptor found in $97 \%$ of peripheral T lymphocytes, ED1 (Serotec, UK) labelling monocytes and immature macrophages, ED2 (Serotec, UK) specific for resident/mature macrophages, CD54 (Pharmingen, USA), which reacts with intracellular adhesion molecule-1 (ICAM-1) expressed in activated macrophages and HLA-DR antibody (Serotec, UK) which recognises MHC class II antigen present in activated macrophages and B lymphocytes.

\section{Results}

At implant retrieval there were no macroscopic signs of a considerable inflammatory reaction in any of the animals and no cellular exudate was formed around the implants.

A thin fibrous capsule, invariably containing inflammatory cells ranging from diffuse to concentrated density, surrounded all implants. Table 1 presents the histological analysis of the interface tissue afterimmunohistochemistry using ED1,ED2, CD54, MHC class II and $\alpha / \beta$ antibodies. A positive stain, although with different intensities depending on the polymers and on the period of implantation, was observed for all the antibodies except for $\alpha / \beta$. The presence of blood vessels was also observed in the majority of the cases.

\section{SEVA-C}

The starch-ethylene vinyl alcohol blend (SEVA-C) showed, within the studied implantation period, a mild inflammatory reaction (Figure 2).

A moderate cellular infiltrate composed of macrophages was observed at the tissue-material interface for all periods 
Table 1. Tissue reaction of subcutaneous implanted starch-based materials after immunohistochemical analysis (0: absent; 1 : sparse; 2 : moderate; 3 : abundant; 4: very Abundant; -: negative; +: positive).

\begin{tabular}{|c|c|c|c|c|c|c|c|}
\hline \multirow[t]{2}{*}{ Material } & \multirow{2}{*}{$\frac{\text { Implantation time }}{\mathrm{d}}$} & \multicolumn{4}{|c|}{ Macrophages } & \multirow{2}{*}{$\begin{array}{c}\text { Lymphocytes } \\
\alpha / \beta\end{array}$} & \multirow{2}{*}{$\frac{\text { Blood vessels }}{\text { CD54 }}$} \\
\hline & & ED1 & ED2 & CD54 & MHC class II & & \\
\hline \multirow[t]{3}{*}{ SEVA-C } & 7 & 2 & 2 & 2 & 2 & 0 & - \\
\hline & 14 & 2 & 2 & 2 & 2 & 0 & + \\
\hline & 21 & 3 & 2 & 2 & 3 & 1 & - \\
\hline \multirow[t]{3}{*}{ SCA } & 7 & 2 & 2 & 2 & $2-3$ & 0 & - \\
\hline & 14 & 2 & 2 & 2 & 2 & 0 & + \\
\hline & 21 & 2 & 2 & 2 & 2 & 0 & + \\
\hline \multirow[t]{3}{*}{$\mathrm{SCA}+10 \% \mathrm{HA}$} & 7 & 2 & 2 & 2 & 2 & 1 & - \\
\hline & 14 & 2 & 2 & 2 & 2 & 1 & - \\
\hline & 21 & $2-3$ & 2 & $2-3$ & 2 & 1 & + \\
\hline \multirow[t]{3}{*}{$\mathrm{SCA}+20 \% \mathrm{HA}$} & 7 & 2 & 2 & 2 & 2 & 1 & + \\
\hline & 14 & $2-3$ & 2 & 2 & 3 & 1 & + \\
\hline & 21 & $2-3$ & 2 & $2-3$ & 3 & 1 & + \\
\hline \multirow[t]{3}{*}{$\mathrm{SCA}+30 \% \mathrm{HA}$} & 7 & 2 & 2 & 2 & $2-3$ & 1 & + \\
\hline & 14 & $2-3$ & 2 & 2 & $2-3$ & 1 & + \\
\hline & 21 & 3 & 2 & 3 & $3-4$ & 1 & + \\
\hline \multirow[t]{3}{*}{ SPCL } & 7 & 3 & 2 & 2 & 3 & 0 & - \\
\hline & 14 & 3 & 2 & 3 & 3 & 1 & - \\
\hline & 21 & 4 & 2 & 3 & 4 & 1 & + \\
\hline \multirow[t]{3}{*}{$\mathrm{SPCL}+10 \% \mathrm{HA}$} & 7 & 2 & 2 & 2 & 3 & 1 & + \\
\hline & 14 & 2 & 2 & 2 & 2 & 1 & + \\
\hline & 21 & 2 & 3 & 2 & 3 & 1 & + \\
\hline \multirow[t]{3}{*}{$\mathrm{SPCL}+20 \% \mathrm{HA}$} & 7 & 3 & 2 & 3 & 3 & 1 & + \\
\hline & 14 & 3 & 2 & 3 & 3 & 1 & + \\
\hline & 21 & 2 & 2 & 3 & 3 & 1 & + \\
\hline \multirow{3}{*}{$\mathrm{SPCL}+30 \% \mathrm{HA}$} & 7 & 2 & 2 & 2 & 2 & 1 & + \\
\hline & 14 & 2 & 2 & 2 & 2 & 1 & + \\
\hline & 21 & 2 & 2 & 2 & 2 & 2 & + \\
\hline
\end{tabular}

of implantation. Recruited macrophages identified using the ED1 antibody were found in moderate amounts and were mainly located in the tissue close to the interface with the material [Figure 2(A)]. After $21 \mathrm{~d}$ of implantation however, the staining intensity increased indicating an increase in cellular number [Figure 2(B)]. Tissue macrophages (ED2 positively stained) were in considerable numbers but dispersed in the surrounding outer layers of tissue [Figure 2(C)]. Antigen presenting cells (APC) expressing MHC class II molecules were distributed throughout the tissue surrounding the SEVA-C implant and also at the tissue-material interface, suggesting that these cells could belong to either macrophage sub-population [Figure 2(D)]. As for ED1 macrophages at $21 \mathrm{~d}$ of implantation the MHC class II staining pattern seemed to be more intense.

Activated macrophages were also identified through the expression of ICAM-1. In contrast to what was expected, due to an increased intensity of the MHC class II staining, the amount of cells expressing ICAM-1 did not seem to change over time. CD54-positive cells were defining the tissue-material interface, like the ED1 macrophages, but they were also dispersed in the surrounding tissues like the ED2 macrophages. Few T lymphocytes were found in the tissue surrounding SEVA-C only at $21 \mathrm{~d}$ of implantation.

\section{SCA and Composites}

The results obtained for the blend of starch with cellulose acetate (SCA), with the lowest level of inflammation for the studied implantation periods, correlated well with in vitro results ${ }^{[51]}$ which showed a lower number of cells from a mixed population of monocytes/macrophages and lymphocytes and a reduced amount of activated macrophages on that material. No T lymphocytes were found at the interface or in the tissues adjacent to the implant. Low numbers of recruited and resident macrophages were observed and seemed to be comparable for all the times of implantation. The staining pattern showed ED1 macrophages at the tissue-material interface [Figure 3(A)] and ED2 macrophages in the outside layer of the tissue [Figure 3(B)].

The cells expressing MHC class II antibody were, in the case of SCA [Figure 3(C)], slightly different to those observed for SEVA-C [Figure 2(D)]. Comparing the staining pattern of ED1 and ED2 macrophages with MHC class II positive cells, it can be suggested that some of both, the recruited and resident macrophages, expressed MHC class II. This statement is particularly valid at $7 \mathrm{~d}$ of implantation (Figure 3). For longer times the intensity of the staining at the interface (comparable to ED1 pattern) decreased. 
A)

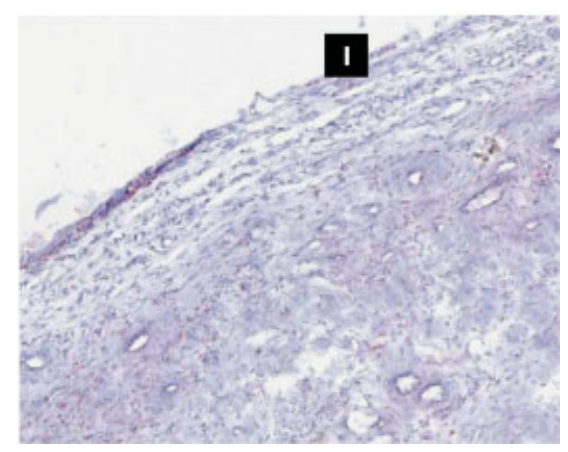

C)

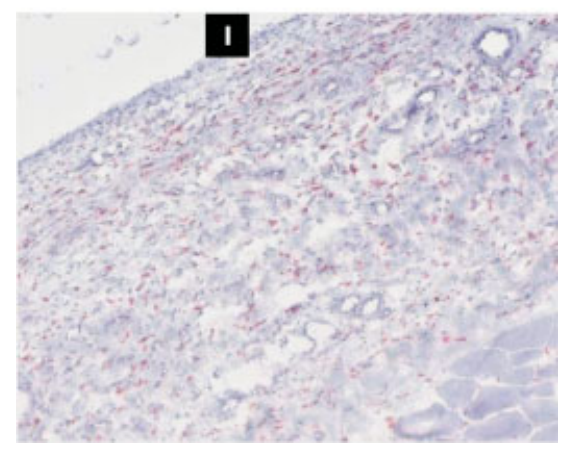

B)

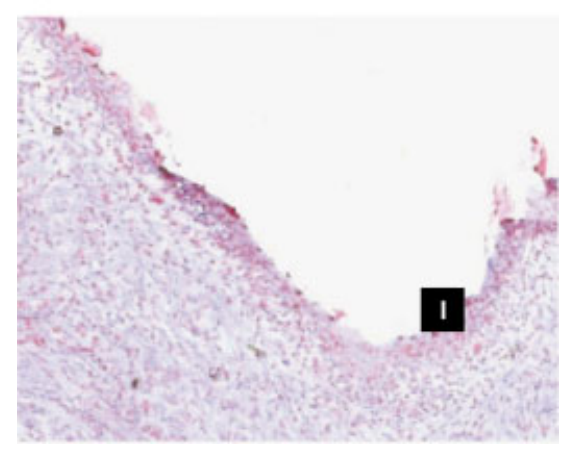

D)

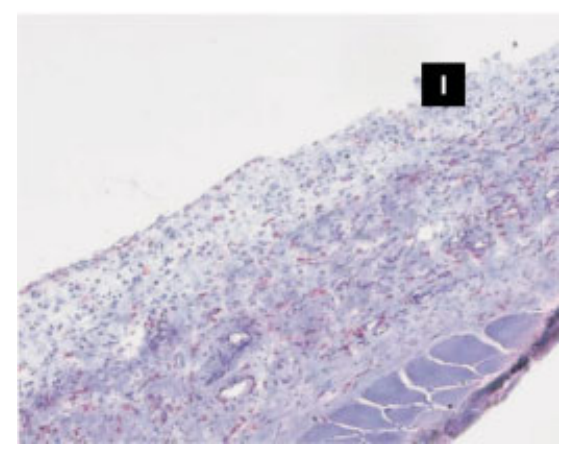

Figure 2. Inflammatory response to SEVA-C. Light micrographs of sections immunocytochemically stained (red cells) for ED1 (A, B); ED2 (C) and MHC class II (D) and counterstained with haematoxylin (purple cells). Explants shown here were taken after 14 $(\mathrm{A}, \mathrm{C}, \mathrm{D})$ and 21 (B) d. I-Tissue-material interface (magnification $\times 10$ ).

The amount of activated macrophages, expressing ICAM-1 at the SCA interface was moderate and comparable to the results obtained for SEVA-C. From day 14, CD54positive cells were present at the tissue-material interface, like at day 7, but also defining blood vessels (Figure 4), which could indicate the influx of inflammatory cells to the site of implantation.

In terms of tissue reaction, the implantation of the SCA reinforced with HA induced a greater effect. While in the presence of the SCA polymer no T lymphocytes were observed, for SCA composites the $\mathrm{T}$ cells which were recruited to the implantation site, although very few at day 7, remained there up to $21 \mathrm{~d}$ (Figure 5).

Surprisingly, SCA with higher percentages of HA (more distinct for 20 and $30 \%$ HA) seemed to stimulate a greater tissue response. It could be considered that, since ED1 staining was more intense, the number of inflammatory cells attracted to the site of implantation of SCA composites,
A)

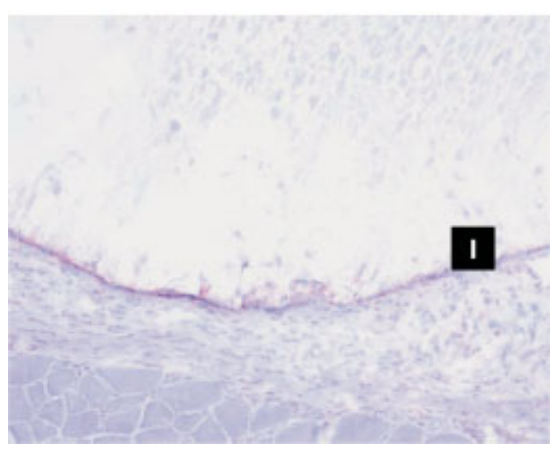

B)

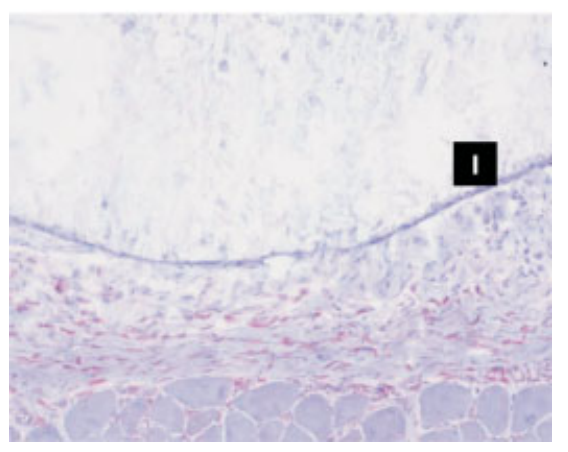

C)

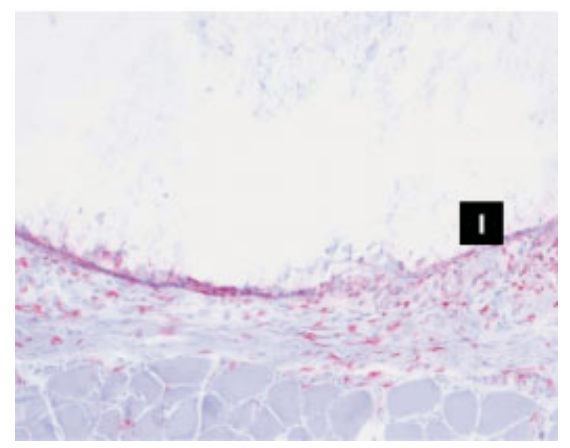

Figure 3. Inflammatory response to SCA. Light micrographs of sections immunocytochemically stained (red cells) for ED1 (A); ED2 (B); MHC class II (C) and counterstained with haematoxylin (purple cells). Explants shown here were taken after $7 \mathrm{~d}$. I-Tissue-material interface (magnification $\times 10$ ). 


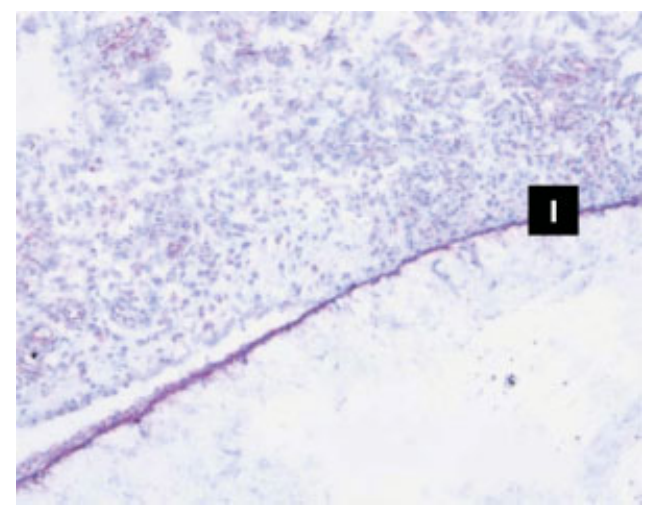

Figure 4. Expression of the adhesion molecule ICAM-1 in a section immunocytochemically stained (red cells) for CD54 and counterstained with haematoxylin (purple cells). SCA was explanted at day 14. Positive macrophages and blood vessels are defined. I-Tissue-material interface (magnification $\times 10$ ).

compared to SCA, was higher particularly at $21 \mathrm{~d}$ of implantation [Figure 6(A)]. Furthermore, ICAM-1 expressing cells were found in the periphery of blood vessels from day 7 for SCA $+20 \%$ HA [Figure 6(B)] and SCA $+30 \%$ HA [Figure $6(\mathrm{C})]$ and only at $21 \mathrm{~d}$ of implantation in the case of SCA + 10\% HA [Figure 6(D)].

The distribution pattern of recruited and resident macrophages did not show significant differences compared to other materials. ED1-positive cells were mainly defining the interface, while ED2-positive cells were dispersed within the surrounding tissue. Cells expressing ICAM-1, however, were more concentrated at the interface at longer implantation periods [Figure 6(B-D)].

The pattern of cells expressing MHC class II molecules was different in the presence of SCA composites compared to the unreinforced material. The different percentages of HA also demonstrated differences; a greater number of cells appeared to express MHC class II for SCA with 20 and $30 \%$ of HA [Figure 7(A) compared to SCA $+10 \%$ HA [Figure 7(B)]. Additionally, after $21 \mathrm{~d}$ of implantation of

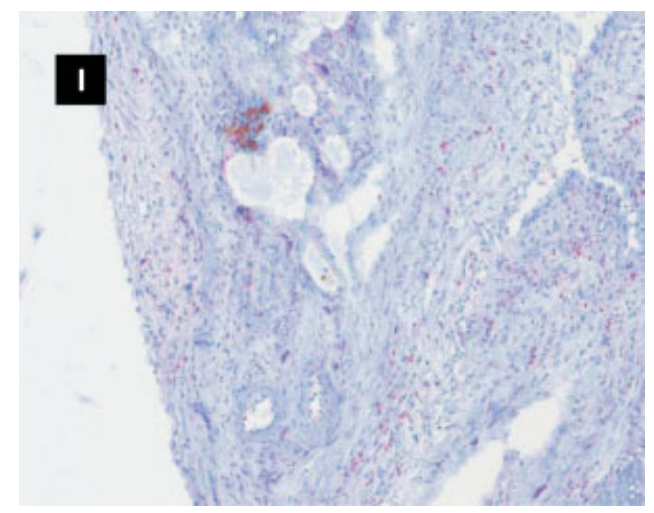

Figure 5. Expression of the $\alpha / \beta$ T-cell antigen receptor in a section immunocytochemically stained (red cells) for T cells and counterstained with haematoxylin (purple cells). SCA $+10 \%$ HA, day 21. I-Tissue-material interface (magnification $\times 10$ ).
A)

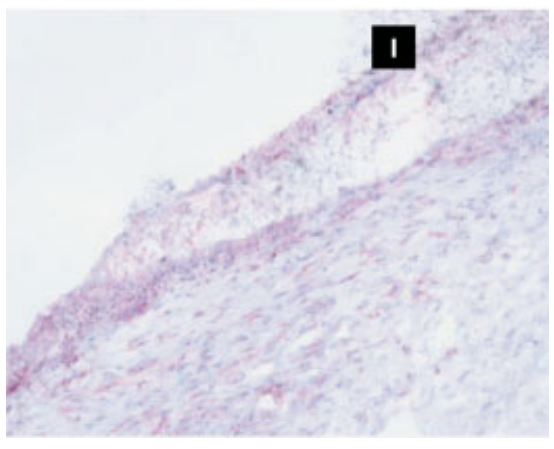

B)

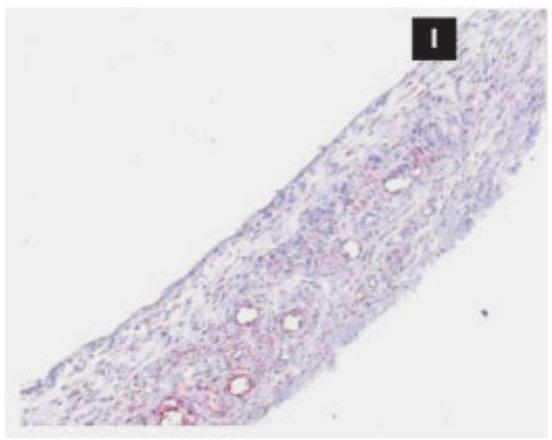

C)

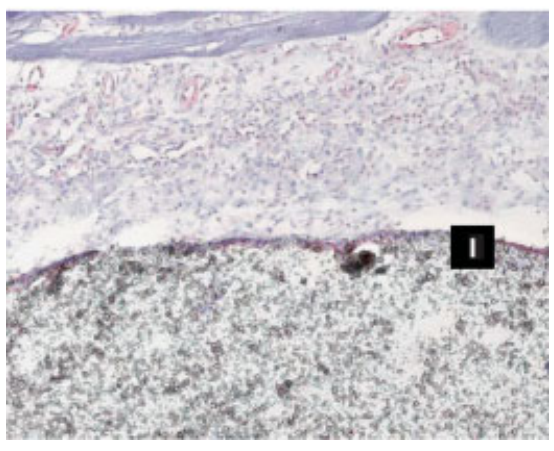

D)

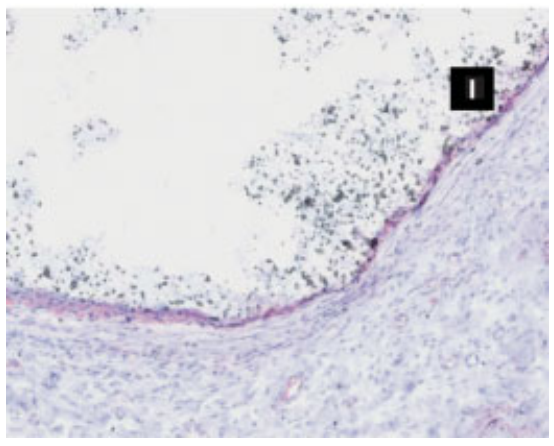

Figure 6. Inflammatory response to SCA composites; (A, D) SCA + 10\% HA; (B) SCA + 20\% HA; (C) SCA + 30\% HA. Light micrographs of sections immunocytochemically stained (red cells) for ED1 (A); CD54 (B, C, D) and counterstained with haematoxylin (purple cells). Explants shown here were taken after (B, C) 7 and (A, D) 21 d. I-Tissue-material interface (magnification $\times 10$ ). 
A)

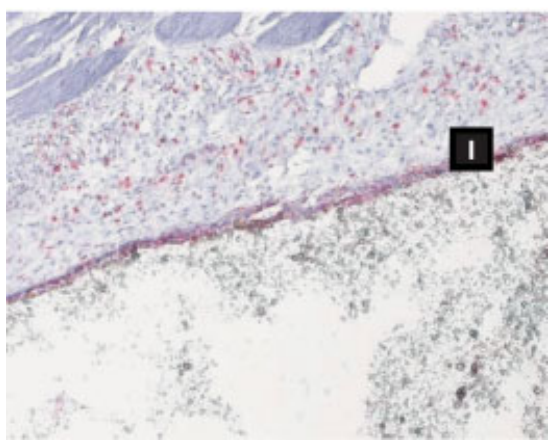

B)

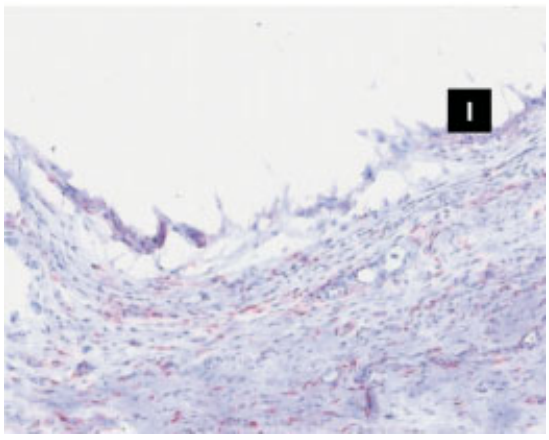

C)

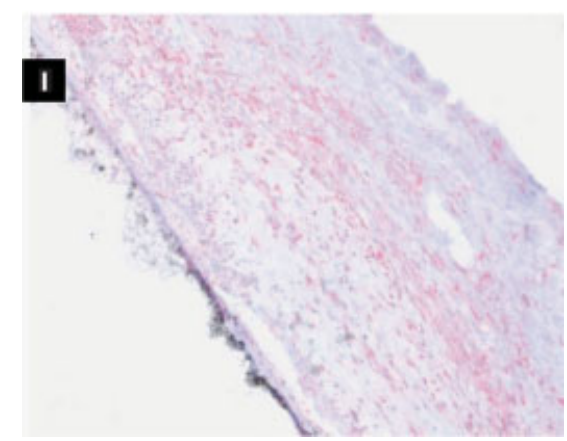

Figure 7. Expression of MHC class II molecule in sections immunocytochemically stained (red cells) for APC and counterstained with haematoxylin (purple cells). (A, C) SCA + 30\% HA; (B) SCA $+10 \%$ HA. Explants shown here were taken after (A) 7 and $(\mathrm{B}, \mathrm{C}) 21 \mathrm{~d}$. I-Tissue-material interface (magnification $\times 10)$.

$\mathrm{SCA}+30 \% \mathrm{HA}$, the concentration of cells expressing MHC class II seems to increase, being dispersed all over the tissue surrounding the implant [Figure 7(C)].

As in the case of SCA, many of the cells expressing MHC class II were probably macrophages as the pattern of staining was very similar to ED1.

\section{SPCL and Composites}

SPCL was the starch-based biomaterial that provoked the strongest tissue reaction. ED1 macrophages were abundant at
A)

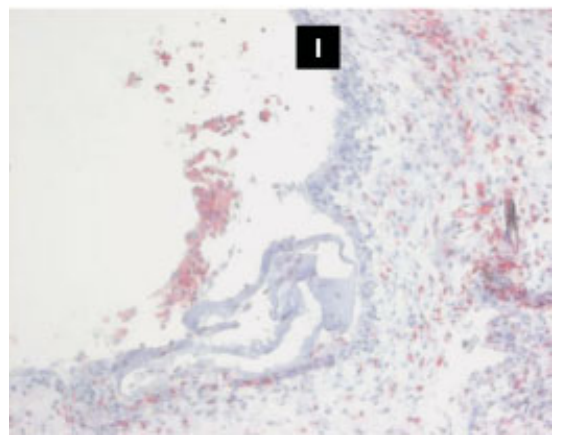

B)

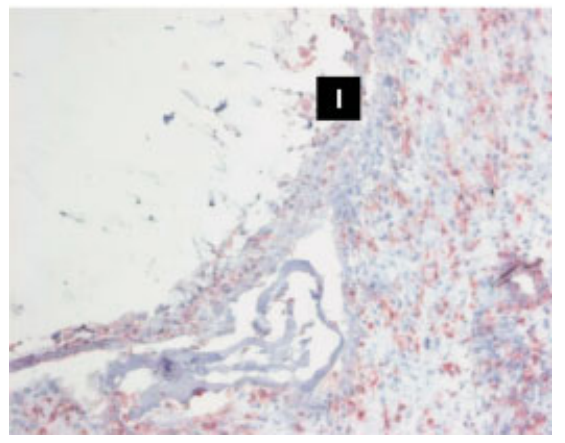

C)

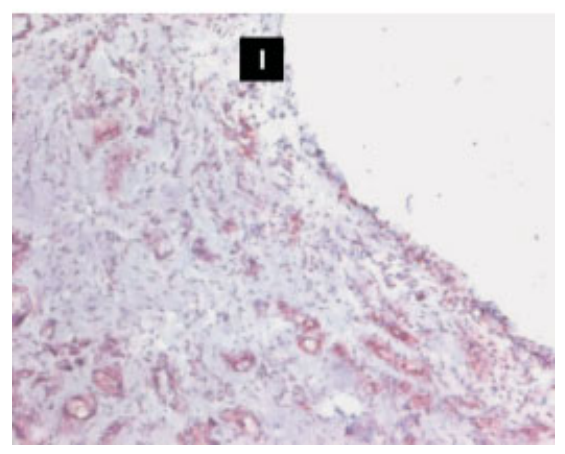

Figure 8. Inflammatory response to SPCL. Light micrographs of sections immunocytochemically stained (red cells) for ED1 (A); MHC class II (B); CD54 (C) and counterstained with haematoxylin (purple cells). Explants shown here were taken after (A, B) 7 and (C) $21 \mathrm{~d}$. I-Tissue-material interface (magnification $\times 10$ ).

the SPCL interfaces from day 7 [Figure 8(A)], persisting for the whole duration of the study. A high staining intensity of the cells expressing MHC class II molecules [Figure 8(B)] was also observed. The more intense positive cell staining was observed for ED1 and MHC class II antibodies in the sections obtained after $21 \mathrm{~d}$ of SPCL implantation.

Although not as abundant as ED1 and MHC class II positive cells, cells expressing ICAM-1 were also found. These were more apparent at later implantation times, demarcating blood vessels at $21 \mathrm{~d}$ of implantation [Figure 8(C)]. 
A)

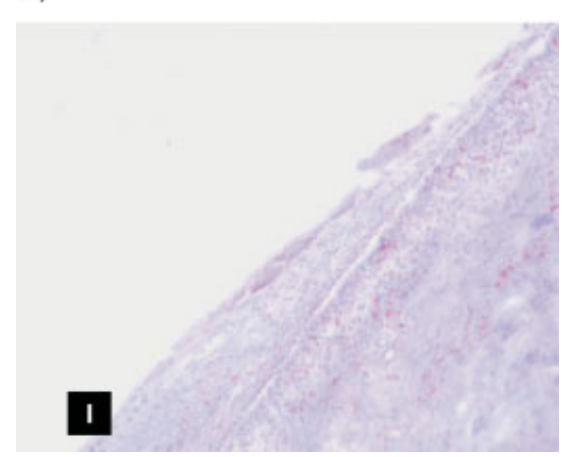

B)

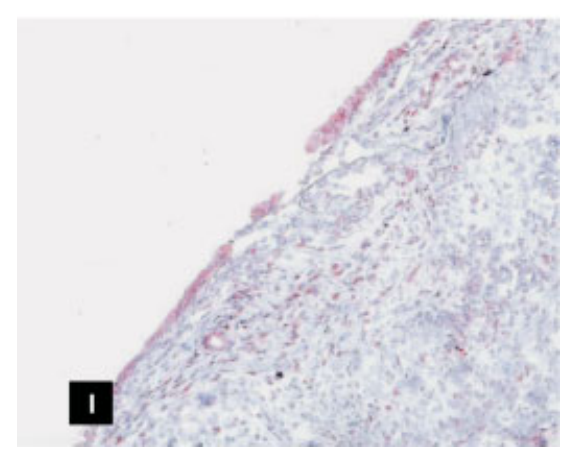

C)

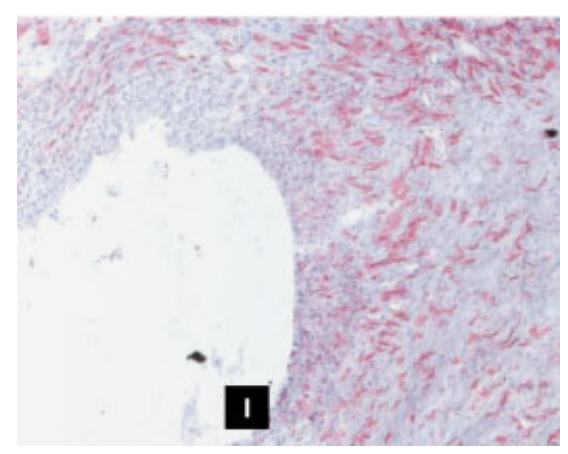

Figure 9. Inflammatory response to SPCL composites; (A, B) SPCL $+30 \%$ HA; (C) SPCL $+10 \%$ HA. (A) Expression of the $\alpha / \beta$ T-cell antigen receptor in a section immunocytochemically stained (red cells) for T cells; Light micrographs of sections immunocytochemically stained (red cells) for ED1 (B); ED2 (C). Cells were counterstained with haematoxylin (purple cells). Explants shown here were taken after (B) 7 and (A, C) 21 d. I-Tissuematerial interface (magnification $\times 10$ ).

Cells marked with ED1 are distributed within the tissue mainly in the close line that describes the material-tissue interface and in the most outer layer. Many of the cells expressing MHC class II corresponded to cells stained with either ED1 or ED2, possibly suggesting that APC could belong to both subpopulations. Comparing the observations for SCA composites, the incorporation of HA in the SPCL polymer seemed to affect the tissue reaction differently. A rare presence of T lymphocytes at the SPCL-tissue interface was noted from day 14. However, in the case of SPCL composites, T lymphocytes were identified at earlier implantation times (from day 7) and at moderate concentrations in the tissues surrounding SPCL $+30 \%$ of HA at $21 \mathrm{~d}$ of implantation [Figure $9(\mathrm{~A})]$.

In terms of recruited cells, the implantation of SPCL composites did not attract as many cells as the unreinforced material, although an intense stain for ED1 antibody seemed to be observed at the SPCL $+20 \%$ HA interface for shorter implantation periods [Figure 9(B)]. Curiously a very similar pattern for activated macrophages and activated endothelium (CD54 positive) was observed between SPCL and its composite reinforced with 20\% HA. These ICAM-1 expressing cells were abundant from day 7 and were observed both at the interface and in the surrounding tissues. At the interface of the other two SPCL composites with 10 and $30 \% \mathrm{HA}$, activated macrophages were found in moderate concentrations in the same pattern of distribution.

ED2-positive cells after $21 \mathrm{~d}$ of the implantation of SPCL $+10 \%$ HA presented a different morphology. These positive cells were present, as in the case of other materials, in the outer layer of the tissue, but were bigger [Figure 9(C)]. For all the other composites, ED2 macrophages were comparable in terms of morphology and pattern of distribution.

A higher concentration of cells expressing MHC class II molecules were observed, as well as for CD54, in the tissues surrounding SPCL $+20 \%$ HA implant. Similar results were also found for SPCL $+10 \%$ HA.

\section{Discussion}

The sequence of wound-healing processes can be subdivided into two phases: the inflammatory phase, which normally takes about 2 weeks, and the repair phase. The presence of an implant can provide a continuous inflammatory stimulus resulting in a prolonged inflammatory phase, which is associated with increased cellular activity and delayed and enhanced tissue repair. Thus, chronic inflammation is characterised by the presence of macrophages, monocytes, lymphocytes and plasma cells with the proliferation of blood vessels and connective tissue. In a final stage, foreign-body giant cells can be found apposed to the biomaterial surface. A granulation tissue is formed, and fibrous encapsulation of the implant occurs. ${ }^{[44,52-54]}$

The aim of this study was to determine the presence of important cell types in the tissue response evoked by starchbased biomaterials subcutaneously implanted in rats. The differential activation and expansion of distinct macrophage populations, the recruitment of $\mathrm{T}$ cells and the upregulation of cell-adhesion molecules were evaluated.

In this study macrophages stained with ED1, immediately migrated within the first days of implantation. For 
some materials their number increased at longer times of implantation; thus, the ED1-positive macrophage layer at the implant interface was shown to vary in thickness depending on the material. Mature tissue macrophages (ED2) were only observed in the loose connective tissue surrounding the capsule of the implants and no significant differences were detected with time except for SPCL $+10 \% \mathrm{HA}$ implanted for $21 \mathrm{~d}$.

Some research ${ }^{[9,55-57]}$ has demonstrated varying behaviour and roles for ED1 and ED2 macrophages. ED1-positive macrophages were shown to accumulate quickly and to be active in phagocytosis, ${ }^{[9,56]}$ while ED2 macrophages accumulated slowly and play a role in regeneration. One study $^{[58]}$ suggested that ED1 macrophages play a role in material resorption because they mainly act at the material interface. Khouw et al. ${ }^{[9]}$ reported that giant cells were never ED2-positive, which could suggest that resident macrophages are not involved in the phagocytosis of implanted biomaterials.

The results obtained for SCA composites in terms of subpopulation distribution, in particular recruited macrophages, are in accordance with previous research, since it was possible to observe that the HA reinforcement of SCA induced stronger ED1 staining. It could be speculated that within the studied implantation periods there was some HA dissolution from the SCA composites. In fact, SCA is the material with higher water uptake capability and a higher access to the inner HA particles within the composite and a greater susceptibility to hydrolysis at the interface polymerHA compared to the bulk of the material. ${ }^{[59]}$ Easier access to those interfaces could facilitate the degradation of the material and the release of HA particles, which might be responsible for recruitment of macrophages with the potential to phagocytose the particles.

The mechanism of cell recruitment at the inflammation site is still poorly defined. Some authors ${ }^{[9]}$ question if ED2 macrophages migrate from the loose connective tissue into the biomaterial where they become activated for phagocytosis, losing their ED2 antigen and becoming ED1-positive cells. Alternatively it has been suggested ${ }^{[10]}$ that vascular recruitment of blood-borne monocytes contributes to the initial macrophage response against the material. In addition, ED2 macrophages capable of expressing MCP-1 ${ }^{[57]}$ were also implied to be involved in the stimulation and recruitment of additional macrophages. ${ }^{[10]}$ The duration of the inflammatory reaction has also been correlated with angiogenesis around implants. ${ }^{[12,13,16,17]}$ In fact, the codependence of inflammation and angiogenesis has been suggested by some authors ${ }^{[24,25]}$ due to the capacity of activated macrophages to release numerous angiogenic factors. ${ }^{[24,26]}$ The up-regulation of adhesion molecules is also known to have significant participation in the process of transvascular migration of the inflammatory infiltrate. ${ }^{[27,28]}$ Phagocytes adhere to endothelium through ICAM-1; thus, the influx of macrophages was analysed considering the expression of ICAM-1 by macrophages and blood vessels. Angiogenesis varied with implantation times and also with the materials implanted. A marked vascular response with macrophages infiltrating was observed in the tissues surrounding SCA and SPCL composites, especially for higher percentages of HA. However, close to the implants in areas of high cellularity, blood vessels were sparse.

The up-regulation of adhesion molecules is useful in the influx of cells. Cell/cell adhesion predominantly involves binding of ICAM-1 to CD11a or CD11b ${ }^{[60]}$ and macrophages require this interaction to form giant cells. Furthermore, the activation of $\mathrm{T}$ cells occurs after antigen presentation by the macrophages with the MHC class II molecule. ${ }^{[53]}$ Activated $\mathrm{T}$ cells secrete cytokines and provide the necessary signals to promote and regulate humoral and cell-mediated immune responses and inflammation. In particular, activated $\mathrm{T}$ cells may secrete lymphokines like IL-4 ${ }^{[32]}$ and IFN- $\gamma,{ }^{[31]}$ two cytokines involved in the regulation of MHC class II molecules and in the formation of FBGC. Previous studies found that at implant interface tissue, ICAM-1 was expressed by giant cells. These multinucleated cells are linked to the phagocytosis of implanted materials and their degradation products, and are often found on the implant side of the membrane but not deeper within the tissue. ${ }^{[16,61]}$

There are other mechanisms by which biodegradable biomaterials can influence the FBGC response, including the effects of surface properties on protein adsorption and macrophage attachment and fusion. The conformation of adsorbed proteins in the tissue biomaterial interface may be responsible for encouraging macrophage fusion into FBGC ${ }^{[62]}$ Some domains of fibronectin have been directly connected to host response and in particular to macrophage adhesion and FBGC formation in vivo. ${ }^{[63]}$ The involvement of adsorbed fibrinogen has been reported in the attraction of phagocytic cells to the surfaces of implanted materials. ${ }^{[64]} \mathrm{It}$ is also known that protein adsorption is related to surface chemistry and/or topography; thus, macrophage activation and formation of foreign-body giant cells may be influenced by the physico-chemical properties of the implant. ${ }^{[18,65]}$ Implants with higher water and carboxylic group content have been shown to inhibit macrophage adhesion and fusion, probably because hydrophobic interactions participate in cell-matrix interactions. ${ }^{[65]}$

An abundant number of activated macrophages expressing ICAM-1 were identified after implantation of some of the starch-based materials; however, no foreign-body giant cells were present at any of the implantation sites. A previous in vitro work ${ }^{[66]}$ revealed that lymphocytes cultured with the materials in study did not produce IFN- $\gamma$, a cytokine involved in the formation of FBGC. In addition, in vivo protein adsorption studies showed that although fibronectin was clearly detected in the immediate implant tissue interface, fibrinogen was not identified in the proximal implant area. ${ }^{[67]}$ Besides these possible explanations, 
the absence of FBGC may be the consequence of the variable rate of degradation of the starch-based material ${ }^{[37]}$ at the time point of the assay, not stimulating high phagocytic activity and also of the materials physical-chemical properties, not appropriate for macrophage adhesion and fusion.

\section{Conclusion}

The in vivo observations validated in vitro results, confirming that the established in vitro models are reliable and could be used to estimate a potential inflammatory reaction provoked by newly developed biomaterials before implantation.

The subcutaneous implantation of starch-based biomaterials in rats demonstrated that the materials possess a weak potential to stimulate an inflammatory reaction. No macroscopic signs of considerable inflammation were observed and no cellular exudate was formed. For some materials the number of recruited macrophages increased at longer times of implantation. Contrarily, mature tissue macrophages were only observed in the loose connective tissue surrounding the capsule of the implants and no significant differences were detected with increasing implantation time except for SPCL $+10 \%$ HA implanted for $21 \mathrm{~d}$. This study also demonstrated a significant increase in antigen-presenting phenotype at the interface with some materials, which could be associated with persistent local chronic inflammation. However, the low number or absence of lymphocytes at some material-tissue interfaces may be indicative of a mild foreign-body reaction against these materials.

SPCL and SCA composites were the materials that stimulated the greatest tissue responses, but in general, biodegradable starch-based materials did not induce a severe reaction at the studied implantation times, which contrasts favourably other types of degradable polymeric biomaterials.

Acknowledgements: The authors gratefully acknowledge the Portuguese Foundation for Science and Technology and the Portuguese Programme PRAXIS XXI for awarding a Ph.D. Grant to A. P. Marques (SFRH/BD1276/2000). This work was also partially supported by FCT Foundation for Science and Technology, through funds from the POCTI and/or FEDER programmes.

[1] M. Jasty, E. Smith, Curr. Opin. Rheumatol. 1992, 4, 204.

[2] W. J. Maloney, R. L. Smith, Instr. Course Lect. 1996, 45, 171.

[3] H. G. Willert, U. Buchhorn, L. Zichner, Arch. Orthop. Trauma Surg. 1980, 97, 197.
[4] H. G. Willert, G. H. Buchhorn, T. Hess, Orthopaedics 1989, 18,350 .

[5] O. Bostman, E. Hirvensalo, J. Makinen, P. Rokkanen, J. Bone Jt. Surg. Br. 1990, 72, 592.

[6] E. J. Bergsma, F. R. Rozema, R. R. Bos, W. C. de Bruijn, J. Oral Maxillofac. Surg. 1993, 51, 666.

[7] S. Santavirta, J. W. Xu, J. Hietanen, A. Ceponis, T. Sorsa, R. Kontio, Y. T. Konttinen, Clin. Orthop. 1998, 352, 16.

[8] O. M. Bostman, J. Bone Jt. Surg. Br. 1991, 73, 679.

[9] I. M. Khouw, P. B. van Wachem, R. J. van der Worp, T. K. van den Berg, L. F. de Leij, M. J. van Luyn, J. Biomed. Mater. Res. 2000, 49, 297.

[10] R. D. Hagerty, D. L. Salzmann, L. B. Kleinert, S. K. Williams, J . Biomed. Mater. Res. 2000, 49, 489.

[11] S. A. Clarke, P. A. Revell, J. Biomed. Mater. Res. 2001, 57, 84.

[12] R. S. Kellar, L. B. Kleinert, S. K. Williams, J. Biomed. Mater. Res. 2002, 61, 226.

[13] K. Jansen, J. F. van der Werff, P. B. van Wachem, J. P. Nicolai, L. F. de Leij, M. J. van Luyn, Biomaterials 2004, 25, 483.

[14] J. A. Parker, X. F. Walboomers, J. W. Von den Hoff, J. C. Maltha, J. A. Jansen, Biomaterials 2002, 23, 3887.

[15] J. A. Parker, X. F. Walboomers, J. W. Von Den Hoff, J. C. Maltha, J. A. Jansen, Tissue Eng. 2003, 9, 117.

[16] N. Al-Saffar, J. T. Mah, Y. Kadoya, P. A. Revell, Ann. Rheum. Dis. 1995, 54, 201.

[17] K. R. Kidd, D. B. Dal Ponte, R. S. Kellar, S. K. Williams, J. Biomed. Mater. Res. 2002, 59, 682.

[18] J. S. Pieper, P. B. van Wachem, M. J. A. van Luyn, L. A. Brouwer, T. Hafmans, J. H. Veerkamp, T. H. van Kuppevelt, Biomaterials 2000, 21, 1689.

[19] J. P. Fisher, J. W. Vehof, D. Dean, J. P. van der Waerden, T. A. Holland, A. G. Mikos, J. A. Jansen, J. Biomed. Mater. Res. 2002, 59, 547.

[20] A. K. Poshusta, J. A. Burdick, D. J. Mortisen, R. F. Padera, D. Ruehlman, M. J. Yaszemski, K. S. Anseth, J. Biomed. Mater. Res. 2003, 64A, 62.

[21] E. M. Ooms, E. A. Egglezos, J. G. Wolke, J. A. Jansen, Biomaterials 2003, 24, 749.

[22] Y. Tabata, Y. Ikada, Adv. Polym. Sci. 1990, 94, 107.

[23] D. S. Kohane, M. Lipp, R. C. Kinney, D. C. Anthony, D. N. Louis, N. Lotan, R. Langer, J. Biomed. Mater. Res. 2002, 59, 450.

[24] C. Sunderkotter, K. Steinbrink, M. Goebeler, R. Bhardwaj, C. Sorg, J. Leukoc. Biol. 1994, 55, 410.

[25] J. R. Jackson, M. P. Seed, C. H. Kircher, D. A. Willoughby, J. D. Winkler, FASEB J. 1997, 11, 457.

[26] C. Sunderkotter, M. Goebeler, K. Schulze-Osthoff, R. Bhardwaj, C. Sorg, Pharmacol. Ther. 1991, 51, 195.

[27] H. Rosen, S. Gordon, J. Exp. Med. 1987, 166, 1685.

[28] S. K. Lo, G. A. Van Seventer, S. M. Levin, S. D. Wright, J. Immunol. 1989, 143, 3325.

[29] S. Santavirta, Y. T. Konttinen, T. Saito, M. Gronblad, E. Partio, P. Kemppinen, P. Rokkanen, J. Bone Jt. Surg. Br. 1990, 72, 597.

[30] M. J. van Luyn, I. M. Khouw, P. B. van Wachem, E. H. Blaauw, J. A. Werkmeister, J. Biomed. Mater. Res. 1998, 39 , 398.

[31] I. M. Khouw, P. B. van Wachem, L. F. de Leij, M. J. van Luyn, J. Biomed. Mater. Res. 1998, 41, 202.

[32] W. J. Kao, A. K. McNally, A. Hiltner, J. M. Anderson, J. Biomed. Mater. Res. 1995, 29, 1267.

[33] R. L. Reis, A. M. Cunha, J. Appl. Med. Polym. 2000, 4, 1.

[34] M. E. Gomes, A. S. Ribeiro, P. B. Malafaya, R. L. Reis, A. M. Cunha, Biomaterials 2001, 22, 883. 
[35] I. Espigares, C. Elvira, J. F. Mano, B. Vázquez, J. San Roman, R. L. Reis, Biomaterials 2002, 23, 1883.

[36] P. B. Malafaya, C. Elvira, A. Gallardo, J. San Roman, R. L. Reis, J. Biomed. Sci., Polym. Ed. 2001, 12, 1227.

[37] H. S. Azevedo, F. M. Gama, R. L. Reis, Biomacromolecules 2003, 4, 1703

[38] P. Artursson, D. Johansson, I. Sjoholm, Biomaterials 1988, 9, 241.

[39] C. Desevaux, C. Girard, V. Lenaerts, P. Dubreuil, Int. J. Pharm. 2002, 232, 119.

[40] C. Desevaux, P. Dubreuil, V. Lenaerts, C. Girard, J. Biomed. Mater. Res. 2002, 63, 772.

[41] S. C. Mendes, R. L. Reis, Y. P. Bovell, A. M. Cunha, C. A. van Blitterswijk, J. D. de Bruijn, Biomaterials 2001, 22, 2057.

[42] V. Souillac, J. C. Fricain, R. Bareille, R. L. Reis, D. Chauveaux, C. Baquey, "Starch Based Copolymers as Biomaterials in vivo Biocompatibility Study", in: Bioceramics, S. Giannini, A. Moroni, Eds., Trans Tech Publications Ltd., Zurich 2001, Vol. 13, p. 433.

[43] D. F. Williams, Mater. Res. Soc. Symp. Proc. 1986, 55, 117.

[44] J. M. Anderson, ASAIO Trans. 1988, 34, 101.

[45] J. M. Anderson, Prob. Gen. Surg. 1994, 11, 147.

[46] B. D. Ratner, A. S. Hoffman, F. J. Schoen, J. E. Lemons, "Biomaterials Science. An Introduction to Materials in Medicine", Academic Press, San Diego 1996.

[47] EU 0400531 (1990), Novamont S.P.A., invs.: C. Bastioli, R. Lombi, G. D. Tredice, I. Guanella.

[48] C. Bastioli, V. Bellotti, L. D. Guidice, G. Gilli, J. Environ. Polym. Degrad. 1993, 1, 181

[49] C. Bastioli, V. Bellotti, A. Rallis, Rheol. Acta 1994, 33, 307.

[50] J. A. Hunt, D. G. Vince, D. F. Williams, J. Biomed. Eng. 1993, 15, 39.
[51] A. P. Marques, R. L. Reis, J. A. Hunt, J. Mater. Sci.: Mater. Med., submitted.

[52] J. M. Anderson, Cardiovasc. Pathol. 1993, 2, 33.

[53] L. Tang, J. W. Eaton, Am. J. Clin. Pathol. 1995, 103, 466.

[54] J. M. Anderson, Annu. Rev. Mater. Res. 2001, 31, 81.

[55] G. Heuff, M. B. van der Ende, H. Boutkan, W. Prevoo, L. G. Bayon, G. J. Fleuren, R. H. Beelen, S. Meijer, C. D. Dijkstra, Scand. J. Immunol. 1993, 38, 10.

[56] I. S. McLennan, Cell Tissue Res. 1993, 272, 193.

[57] N. P. Rhodes, J. A. Hunt, D. F. Williams, J. Biomed. Mater. Res. 1997, 37, 481.

[58] N. Terada, L. M. Bjursten, G. Lundborg, J. Mater. Sci.: Mater. Med. 1997, 8, 391.

[59] C. M. Vaz, R. L. Reis, A. M. Cunha, Biomaterials 2002, 23, 629.

[60] M. A. Arnaout, Blood 1990, 75, 1037.

[61] N. Al-Saffar, Y. Kadoya, P. Revell, J. Mater. Sci.: Mater. Med. 1994, 5, 813.

[62] D. Lickorish, J. Chan, J. Song, J. E. Davies, Eur. Cell Mater. 2004, $8,12$.

[63] W. J. Kao, D. Lee, Biomaterials 2001, 22, 2901.

[64] W. J. Hu, J. W. Eaton, T. P. Ugarova, L. Tang, Blood 2001, 98 , 1231.

[65] K. Smetana, Jr., J. Sulc, Z. Krcova, Exp. Mol. Pathol. 1987, 47, 271.

[66] A. P. Marques, R. L. Reis, J. A. Hunt, J. Biomed. Mater. Res. A 2004, 71, 419.

[67] C. M. Alves, A. P. Marques, R. L. Reis, J. A. Hunt, in: In Vitro and In Vivo Protein Adsorption Onto Starch-Based Materials and the Effect on Inflammatory Cell Recruitment, 30th Annual Meeting of The Society for Biomaterials, Memphis, USA 2005, p. 604. 